\title{
Regional Water Circulation Health Evaluation System Based on Artificial Neural Network
}

\author{
Chunming Lv, Hui Zhang, Xiao Wang, Junliang Liu* \\ Urban Construction Institute, Hebei Agricultural University, Baoding 071001, China
}

Corresponding Author Email: cjljl@hebau.edu.cn

https://doi.org/10.18280/ijdne.150211

Received: 2 September 2019

Accepted: 10 December 2019

\section{Keywords:}

$B P$ artificial neural network, healthy regional

water circulation, evaluation index

\begin{abstract}
Whether the urban water circulation is healthy or not is an issue that must be considered for achieving the sustainable development of urban society. Before promoting the urban water circulation health system for Hebei Province, it is necessary to evaluate the status of water circulation in this Province. First of all, this paper establishes a regional water circulation health evaluation index system for Hebei Province, and then it builds a regional water circulation health evaluation model for Hebei based on BP artificial neural network. Finally, the evaluation results of water circulation health in Hebei province during the period of 2004-2017 are obtained. This evaluation model can provide background support for the ecological civilization construction and sustainable development of Hebei Province, and serve as a strategic basis for solving urban water problems.
\end{abstract}

\section{INTRODUCTION}

Prefecture-level cities in the Beijing-Tianjin-Hebei region are seeking regional cooperation to promote the transfer of population and industries and exert the potential of inter-basin water diversion. This is the only way to achieve the sustainable development of the Beijing-Tianjin-Hebei region [1]. Despite being a typical water-scarce province itself, Hebei has always been playing the role of ensuring the Capital's water use safety and protecting the water ecological environment [2]. With the advancement of ecological civilization in the Beijing-TianjinHebei region, some problems have also emerged, such as unreasonable discharge of various types of wastewater from production and life, contradictions between the supply and demand of water resources and tensions in the use of water resources due to incomplete supporting facilities. Water circulation problems keep emerging in the process of urbanization, showing that urban water problems are essentially the consequences of the vicious circle of the urban water system. Therefore, the government and relevant departments are gradually developing a healthy and benign circulation mechanism for the urban water system so as to achieve sustainable use of urban water resources [3, 4].

Compared with regional water circulation health evaluation, many scholars have paid more attention to the evaluation of water resources and water resource carrying capacity. At present, there are many methods for evaluating water resources at home and abroad. For example, Fang et al. [5] used the binary index method and the reduction index method to analyze the causes of water resources overload from the perspectives of water resources development and utilization, control capacity and utilization efficiency, etc. Liu et al. [6] used the weighted Mahalanobis distance and the grey ideal solution model to evaluate the resilience of the regional agricultural water and soil resources system and put forward countermeasures and suggestions to improve the utilization rate of water and land resources. Fang [7] applied system dynamics and the WCCI evaluation method to evaluate Pakistan's water resources. Meng et al. [8] selected indicators from four dimensions, namely economy, society, ecological environment and water resources and used the fuzzy comprehensive evaluation method to evaluate the water resources carrying capacity of the basin. Zhang et al. [9] applied the cloud model evaluation method to evaluate the health status of water circulation in the Beijing-Tianjin-Hebei region from four perspectives - water ecology, quality, amount and utilization, and considered the randomness and ambiguity of the evaluation. The study was able to evaluate the proportion of each grade in detail, but there were also problems. For example, the random error of an index will have greater impact on the evaluation results of each layer as the random error increases.

Although the society has increasingly high demand for healthy water circulation and there are more and more studies on this topic, there has not been a clear definition of what is healthy water circulation, nor has there been any standard or complete evaluation system for water health circulation [10]. In view of this, this paper attempts to build a complete water circulation health evaluation system. By reference to the cloud model evaluation method and considering the actual situation of Hebei Province, this paper incorporates another three evaluation dimensions, namely society, economy and water management, in addition to the two existing dimensions water resources and ecological environment, and then builds a complete water circulation health evaluation system using the BP neural network [11] evaluation method, which can continuously modify the weights to control the error within a relatively small range. By evaluating and analyzing the output results of the system, we will be able to work out practical and effective methods to solve the contradiction between the supply and demand of water resources. Therefore, this study provides a technical basis for the construction of a regional water circulation health system.

The improvement of urban water circulation is a necessary 
step in the process of urban development. In the urban development of Hebei Province, decisions have to be made on the direction and intensity of water circulation and utilization. The health status of water circulation will be used as an important basis in the decision-making process [12]. To this end, considering the actual situation of Hebei, this paper establishes a BP neural network model for evaluation of regional water circulation health in Hebei. Then by calculating the index data of Hebei Province during 2004-2017 through the model, this paper obtains the regional water circulation health index, and evaluates and analyzes the result.

\section{ESTABLISHMENT OF THE EVALUATION INDEX SYSTEM}

The regional water circulation system is a complex system composed of many factors and covering a wide range of fields. These factors and fields interact and constrain each other, which directly or indirectly reflects the overall state of regional water circulation [13]. The foundation for comprehensive evaluation is the establishment of an evaluation index system [14].

The BP neural network-based evaluation index system for water circulation health in Hebei Province is composed of 3 layers, namely the target layer, the factor layer and the index layer [15]. The main goal of social development is the comprehensive and coordinated development of society, economy, and ecology; therefore, this paper starts from the relationships among water resources, society, economy, and ecological environment, and takes the regional water circulation health index of Hebei as the target layer, and the status of regional water circulation health (mainly consisting of society, economy, ecological environment, water resources environment and water management, etc.) as the factor layer. In the actual evaluation, this paper analyzes the status of water circulation health based on data within a certain period of time. The index layer specifically consists of influencing indices to the factor layer [16].

Considering the complexity and practicality of the urban water circulation health evaluation system, the indices selected for the index layer should meet the following 4 criteria: (1) objectivity: the indices selected should reflect the status of water circulation health in Hebei Province to the greatest extent; (2) availability: when used to track the status of the water circulation health in Hebei Province, the indices should be constantly available and easily accessible; (3) quantifiability: from the mathematical perspective, quantitative analysis of indices is more credible, executable and convenient than qualitative analysis for the evaluation of urban water circulation health [17]; (4) comprehensiveness: expert research or materials collection should be carried out to help establish the evaluation index system [18]. This study analyzes relevant research results both at home and abroad, follows the principles for establishment of the evaluation index system and considers the importance of each index to the status of regional water circulation health [19].

Therefore, 15 evaluation indices are selected in this study to reflect the status and trend of urban water circulation health, namely natural population growth rate, urbanization rate, GDP per capita, Engel's coefficient for residents, annual energy consumption per unit of GDP, urban public green land area per capita, proportion of ecological water consumption in total water consumption, green space rate of built district, forest coverage, water resources per capita, proportion of investment in wastewater treatment projects in GDP, urban sewage treatment rate and groundwater utilization rate. After considering the interrelationship between the index layer and the factor layer, an evaluation index system is established for the regional water circulation health in Hebei (see Table 1).

Table 1. Evaluation index system for the regional water circulation health in Hebei Province

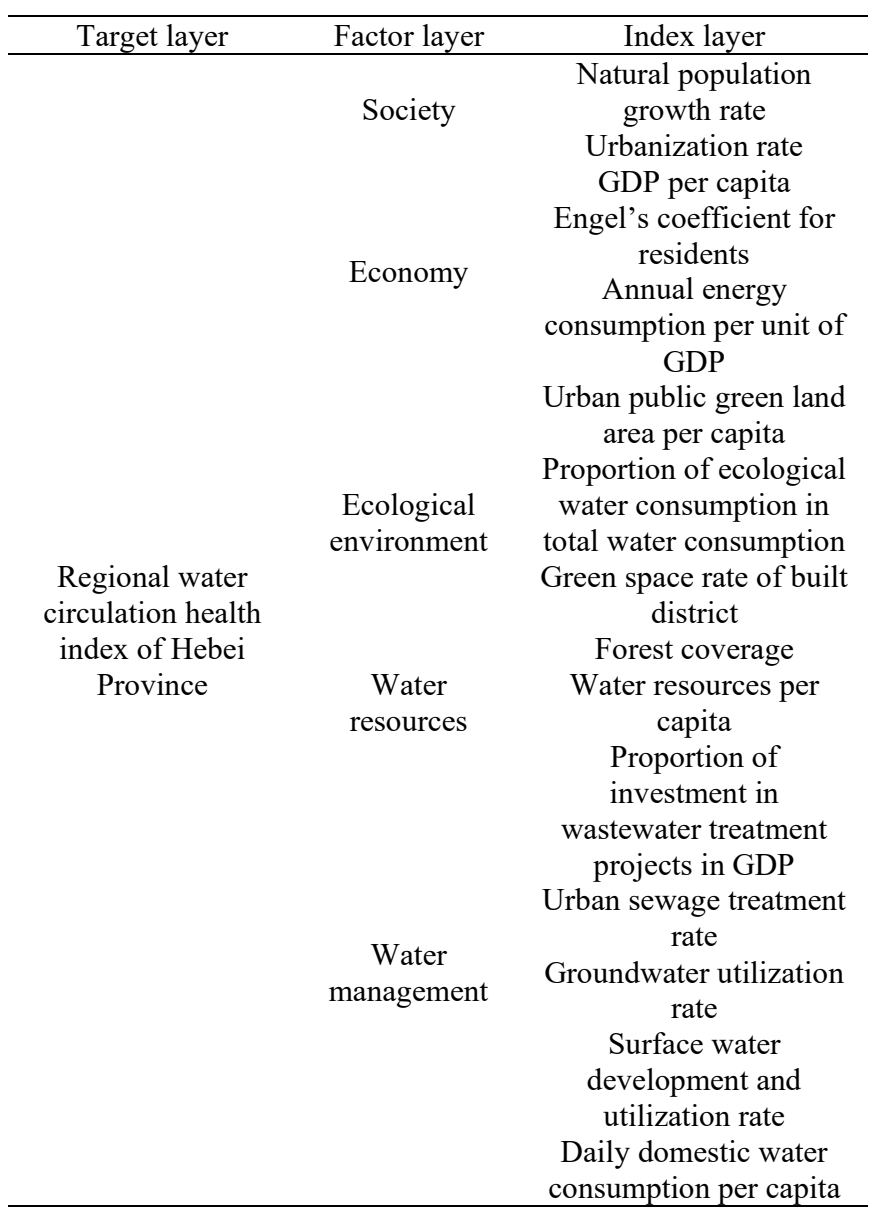

\section{ESTABLISHMENT OF THE EVALUATION MODEL}

Artificial neural network (ANN) is a complex, non-linear, adaptive and parallel information processing network structure composed of a large number of interconnected processing elements [20]. A BP neural network model consists of many neurons. Each neuron has only one output but multiple connecting channels for input, each of which corresponds to only one weight [21]. BP neural networks can be divided into feed-forward neural network and feedback neural network [22]. This network model has many advantages such as strong self-learning ability, high problem solving efficiency, fast calculation speed and wide adaptability, etc. [23]

\subsection{Determination of the network structure of the evaluation model}

A BP neural network is mainly determined by the numbers of neurons in the input layer, the hidden layer and the output layer.

The neural network model for evaluation of water circulation health in Hebei takes each influencing index in 
each set of data as input and the regional water circulation health index as the output, so there are 16 neurons in the input layer and 1 in the target layer. For a more complex BP neural network, the number of hidden layers also needs to be determined through calculation [24]. The number of neurons in the hidden layer is determined by formula (1):

$$
j=\sqrt{i+k}+a
$$

where, $a$ is a constant between $1-10 ; i$ is the number of neurons in the input layer; $k$ is the number of neurons in the output layer; and $j$ is the number of neurons in the hidden layer.

The learning samples are input into the network model. Through repeated network learning, the optimal number of neurons in the hidden layer in the BP neural network is found, which is 9 .

In summary, the topological structure of the BP neural network for evaluation of water circulation health in Hebei is established, as shown in Figure 1.

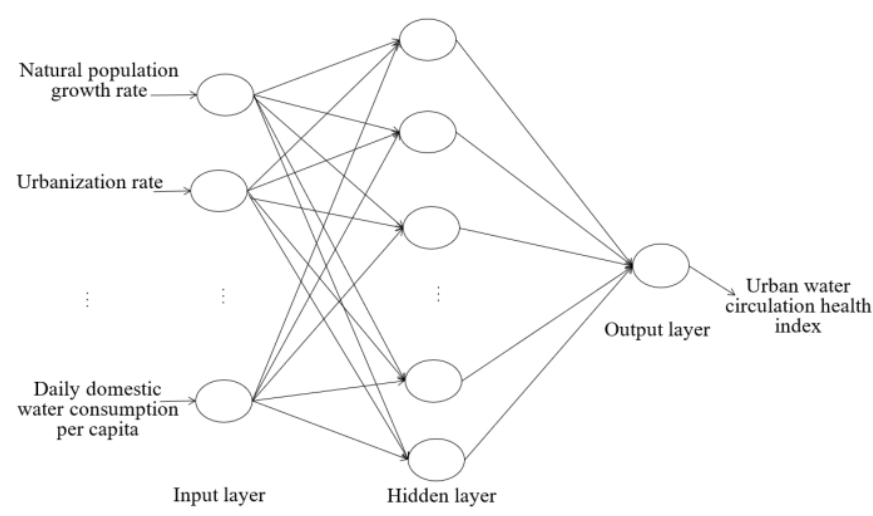

Figure 1. Topological structure of the BP neural network for evaluation of water circulation health in Hebei

\subsection{Selection of the activation function and learning rate of the evaluation model}

The information undergoes forward propagation in the input layer, hidden layer, and output layer of the BP network model, and under the action of the Sigmoid function in the hidden layer and the output layer, the result is output. The Sigmoid activation function is expressed in the form of formula (2):

$$
f(x)=\frac{1}{\left(1+e^{-x}\right)}
$$

The learning rate is an important element in establishing the BP neural network model. If the learning rate is low, the convergence speed will be slow; if it is too high, there will be intense oscillation of iterations. The fixed rate method is relatively simple - a relatively low learning rate is selected to ensure the stability of the system. The adaptive rule is to give the current learning rate $\theta$ a variation $\Delta \theta$ after each or several weight iterations:

When $\Delta E<0$ :

$$
\Delta \theta=a \theta
$$

When $\Delta E \geq 0$ :

$$
\Delta \theta=-b \theta
$$

where, $\Delta E$ is the variation of the network error $E$, and $a$ and $b$ are appropriate constants.

After learning and training, it is found that the effect is ideal when the learning rate of the BP neural network for evaluation of water circulation health in Hebei is 0.01 .

\subsection{Normalization of raw data}

In the comprehensive evaluation on the regional water circulation health, it is difficult to compare the indicators directly because their metrics are different. Therefore, these data have to be normalized before the comprehensive evaluation. This paper adopts the Sigmoid function as the transfer function to normalize the data in the BP neural network. In order to make $|x|$ fall within a small range, the raw data are normalized into the range of $[0,1]$. The normalization formula is shown in (5):

$$
P_{n}=\frac{\left(p-p_{\min }\right)}{\left(p_{\max }-p_{\min }\right)}
$$

where, $p$ is the set of the standard value of an index (the specified value of an evaluation index) and the data of the index in Hebei during 2004-2017, $p_{\max }$ and $p_{\min }$ are the maximum and minimum values in this dataset, and $p_{n}$ is the output of normalization.

\subsection{Graded quantification of data}

3.4.1 Graded quantification of the regional water circulation health index for cities in Hebei

The BP neural network model for evaluation of regional water circulation health in Hebei finally outputs the regional water circulation health index from 2004 to 2017 . The model then performs evaluation by grade according to the range which the quantitative data output fall into. There are 5 grades for the regional water circulation health index of Hebei Province. The first grade of the regional water circulation health index is set as $[0.800,1]$, and then the following grades are determined by the grading function. The grading function is shown in formula (6):

$$
\begin{gathered}
Q_{1}=0.800 \\
Q_{i+1}=Q_{i}-i \times \frac{\left(1-Q_{i}\right)}{(i+1)}
\end{gathered}
$$

where, $2 \leq i \leq 5$.

After calculation, the ranges for the grades of regional water circulation health index are obtained, as listed in Table 2.

Table 2. Grading scale for the regional water circulation health index of Hebei Province

\begin{tabular}{cc}
\hline Grade & Range \\
\hline Grade 1 (circulation is very healthy) & {$[0.800,1]$} \\
Grade 2 (circulation is healthy) & {$[0.693,0.800]$} \\
Grade 3 (circulation is relatively healthy) & {$[0.528,0.693]$} \\
Grade 4 (circulation is unhealthy) & {$[0.329,0.528]$} \\
Grade 5 (circulation is poor) & {$[0,0.329]$} \\
\hline
\end{tabular}

3.4.2 Graded quantification of the standard values of the indices

After being normalized, the standard values of the indices should also be graded when they are input as learning samples, so that they will match the grade ranges of the water 
circulation health index of Hebei and be accepted by the BP neural network. The graded quantification of the standard values of indices is carried out as follows according to the characteristics of the standard values:

(1) When the range of the index standard value is $[M, 1]$, where $M \neq 0$ :

$$
\begin{gathered}
A_{l}=M \\
A_{i}=A_{i-1}-\frac{i \times A_{i-1} \times\left(1-A_{i-1}\right)}{(i+1)} \\
2 \leq i \leq 5 \text { and } M \neq 1 \\
A_{i}=1-0.5 \times i \\
2 \leq i \leq 5 \text { and } M=1
\end{gathered}
$$

(2) When the range of the index standard value is $[0, N]$, where $N \neq 1$ :

$$
\begin{gathered}
A_{l}=N \\
A_{i}=A_{i-1}+\frac{i \times 0.2 \times\left(1-A_{1}\right)}{(i+1)} \\
2 \leq i \leq 5 \text { and } N \neq 0 \\
A_{i}=0+0.5 \times i \\
2 \leq i \leq 5 \text { and } N=0
\end{gathered}
$$

(3) When the range of the index standard value is [M, N], where $M \neq 0$ and $N \neq 1$ :

$$
\begin{gathered}
A_{l}=N \\
A_{i}=A_{i-1}+\frac{i \times 0.2 \times\left(1-A_{1}\right)}{(i+1)} \\
2 \leq i \leq 5
\end{gathered}
$$

At the same time, the normalized index values from 2004 to 2017 are processed as follows:

$$
\text { If } X \geq M, Y=X
$$

Table 3. Standard values of the indices in the water circulation health evaluation model for Hebei Province

$$
\text { If } X<M, Y=\frac{(M-X+N)}{(M+N)}
$$

where, $X$ is the normalized index value, and $Y$ is the output result after processing.

\section{EMPIRICAL ANALYSIS}

This section evaluates the status of urban water circulation health in Hebei Province during the period of 2004-2017 by using the established neural network model for evaluation of water circulation health.

\subsection{Learning of the evaluation model}

Before the learning of the BP neural network, it is necessary to carry out normalization and graded quantification of the standard values of the indices in the learning samples (see Table 3).

After normalization and graded quantification of the standard values of the indices, learning samples were generated (see Table 4), which were then input into the BP neural network model for evaluation of urban water circulation health in Hebei. Afterwards, the network started learning and

\begin{tabular}{|c|c|c|}
\hline Index & Unit & Range of standard value \\
\hline Natural population growth rate & $\%$ & {$[0,20]$} \\
\hline Urbanization rate & $\%$ & {$[5,100]$} \\
\hline GDP per capita & $10^{3}$ Yuan & {$[0.5,8]$} \\
\hline Energy consumption per unit of GDP & tce $/ 10,000$ Yuan & {$[0.5,3.0]$} \\
\hline Engel's coefficient for residents & $\%$ & {$[20,70]$} \\
\hline Urban sewage treatment rate & $\%$ & {$[50,100]$} \\
\hline Groundwater development and utilization rate & $\%$ & {$[5,100]$} \\
\hline Surface water utilization rate & $\%$ & {$[5,100]$} \\
\hline Daily domestic water consumption per capita & $\mathrm{L} /($ person$\cdot$ day) & {$[80,300]$} \\
\hline Proportion of investment in wastewater treatment projects in GDP & $\%$ & {$[0.1,4]$} \\
\hline Water resources per capita & $\mathrm{m}^{3} /$ person $\cdot$ year & {$[100,8000]$} \\
\hline Green space rate of built district & $\%$ & {$[15,60]$} \\
\hline Park green area per capita & $\mathrm{m}^{2} /$ person & {$[1,20]$} \\
\hline Proportion of ecological water consumption in total water consumption & $\%$ & {$[0.1,3]$} \\
\hline Forest coverage & $\%$ & {$[1,60]$} \\
\hline
\end{tabular}
training. It is stipulated for this network model that if the network error $E$ is less than 0.1 , the network training will be regarded as meeting the learning accuracy requirement. After the learning of the BP neural network model for 1000 times, the network error E reached 0.0086 , which met the accuracy requirement, so the training was over. The standard values of the regional water circulation health indices of Hebei Province were input into the network model for simulation. Finally, 4 samples were taken to test the model. After 800 times of learning, the corresponding output values of the water circulation health indices were $0.792,0.670,0.526$ and 0.304 . The results show that the actual output was very close to the expected output.

Table 3. Standard values of the indices in the water circulation health evaluatir

Note: The data in this table are mainly from the National Bureau of Statistics database - National Data, China Urban Construction Statistical Yearbook, Hebei Economic Yearbook, Hebei Economic and Social Development Statistical Bulletin, Integrated Wastewater Discharge Standard (GB8978-1996 ), Farmland Irrigation Water Quality Standard (GB5804-92), Environmental Quality Standards for Surface Water (GB3838-2002), Hygienic Standard for Grains (GB271581) and National Ecological Garden City Standard, etc.

\subsection{Evaluation on the regional water circulation health of the cities in Hebei Province}

Through the necessary normalization and graded quantification of the raw data, the index data of Hebei Province during the period from 2004 to 2017 were transformed into operational data that were acceptable to the model (see Table 5). The processed data were then input into 
the model that was trained in the learning stage, and the values of the regional water circulation health indices of Hebei
Province from 2004 to 2017 were obtained (see Table 6).

Table 4. Learning samples for the water circulation health evaluation model for Hebei Province

\begin{tabular}{|c|c|c|c|c|}
\hline Index & $\begin{array}{l}\text { Grade } 4-5 \\
\text { boundary }\end{array}$ & $\begin{array}{l}\text { Grade 3-4 } \\
\text { boundary }\end{array}$ & $\begin{array}{l}\text { Grade } 2-3 \\
\text { boundary }\end{array}$ & $\begin{array}{l}\text { Grade 1-2 } \\
\text { boundary }\end{array}$ \\
\hline Natural population growth rate & 0.500 & 0.750 & 0.850 & 0.950 \\
\hline Urbanization rate & 0.632 & 0.737 & 0.842 & 0.947 \\
\hline GDP per capita & 0.067 & 0.133 & 0.333 & 0.733 \\
\hline Energy consumption per unit of GDP & 0.400 & 0.600 & 0.720 & 0.920 \\
\hline Engel's coefficient for residents & 0.400 & 0.600 & 0.700 & 0.800 \\
\hline Urban sewage treatment rate & 0.400 & 0.800 & 0.900 & 0.940 \\
\hline Groundwater development and utilization rate & 0.676 & 0.794 & 0.912 & 0.971 \\
\hline Surface water utilization rate & 0.421 & 0.632 & 0.842 & 0.947 \\
\hline Daily domestic water consumption per capita & 0.591 & 0.682 & 0.818 & 0.909 \\
\hline $\begin{array}{c}\text { Proportion of investment in wastewater treatment } \\
\text { projects in GDP }\end{array}$ & 0.114 & 0.203 & 0.278 & 0.367 \\
\hline Water resources per capita & 0.333 & 0.444 & 0.556 & 0.667 \\
\hline Green space rate of built district & 0.158 & 0.368 & 0.474 & 0.579 \\
\hline Park green area per capita & 0.241 & 0.483 & 0.655 & 0.828 \\
\hline $\begin{array}{c}\text { Proportion of ecological water consumption in total } \\
\text { water consumption }\end{array}$ & 0.153 & 0.322 & 0.576 & 0.661 \\
\hline Forest coverage & 0.154 & 0.359 & 0.487 & 0.744 \\
\hline Regional water health index for Hebei Province & 0.329 & 0.528 & 0.693 & 0.800 \\
\hline
\end{tabular}

Table 5. Calculated data of the regional water circulation health indices of Hebei Province during 2004-2017

\begin{tabular}{|c|c|c|c|c|c|c|c|c|c|c|c|c|c|c|}
\hline Index & 2004 & 2005 & 2006 & 2007 & 2008 & 2009 & 2010 & 2011 & 2012 & 2013 & 2014 & 2015 & 2016 & 2017 \\
\hline $\begin{array}{l}\text { Natural population } \\
\text { growth rate }\end{array}$ & 0.087 & 1.000 & 0.476 & 0.560 & 0.746 & 0.833 & 0.813 & 0.702 & 0.560 & 0.242 & 0.155 & 0.000 & 0.198 & 0.413 \\
\hline Urbanization rate & 0.000 & 0.039 & 0.100 & 0.183 & 0.272 & 0.372 & 0.416 & 0.478 & 0.544 & 0.616 & 0.683 & 0.794 & 0.906 & 1.000 \\
\hline GDP per capita & 0.000 & 0.066 & 0.127 & 0.218 & 0.319 & 0.367 & 0.492 & 0.653 & 0.732 & 0.803 & 0.836 & 0.844 & 0.929 & 1.000 \\
\hline $\begin{array}{l}\text { Energy consumption } \\
\text { per unit of GDP }\end{array}$ & 1.000 & 0.945 & 0.891 & 0.836 & 0.736 & 0.655 & 0.600 & 0.345 & 0.182 & 0.164 & 0.127 & 0.082 & 0.036 & 0.000 \\
\hline $\begin{array}{l}\text { Engel's Coefficient } \\
\text { for households }\end{array}$ & 1.000 & 0.815 & 0.764 & 0.759 & 0.829 & 0.736 & 0.632 & 0.753 & 0.736 & 0.187 & 0.128 & 0.119 & 0.125 & 0.000 \\
\hline $\begin{array}{l}\text { Sewage treatment } \\
\text { rate }\end{array}$ & 0.000 & 0.159 & 0.443 & 0.443 & 0.475 & 0.581 & 0.582 & 0.562 & 0.380 & 0.326 & 0.353 & 0.486 & 0.780 & 1.000 \\
\hline $\begin{array}{l}\text { Surface water } \\
\text { utilization rate }\end{array}$ & 0.406 & 0.484 & 0.879 & 1.000 & 0.394 & 0.676 & 0.445 & 0.310 & 0.000 & 0.326 & 0.999 & 0.937 & 0.210 & 0.988 \\
\hline $\begin{array}{l}\text { Groundwater } \\
\text { utilization rate }\end{array}$ & 0.345 & 0.679 & 1.000 & 0.726 & 0.286 & 0.417 & 0.560 & 0.381 & 0.000 & 0.155 & 0.810 & 0.321 & 0.030 & 0.104 \\
\hline $\begin{array}{l}\text { Proportion of } \\
\text { investment in } \\
\text { wastewater } \\
\text { treatment projects in } \\
\text { GDP }\end{array}$ & 0.514 & 0.969 & 0.442 & 0.671 & 1.000 & 0.179 & 0.000 & 0.345 & 0.155 & 0.183 & 0.226 & 0.243 & 0.461 & 0.822 \\
\hline $\begin{array}{c}\text { Daily domestic } \\
\text { water consumption } \\
\text { per capita }\end{array}$ & 1.000 & 0.979 & 0.553 & 0.299 & 0.286 & 0.278 & 0.214 & 0.266 & 0.325 & 0.313 & 0.000 & 0.078 & 0.533 & 0.193 \\
\hline $\begin{array}{c}\text { Water resources per } \\
\text { capita }\end{array}$ & 0.457 & 0.293 & 0.066 & 0.160 & 0.483 & 0.317 & 0.284 & 0.408 & 1.000 & 0.535 & 0.000 & 0.212 & 0.752 & 0.224 \\
\hline $\begin{array}{c}\text { Green space rate of } \\
\text { built district }\end{array}$ & 0.000 & 0.118 & 0.237 & 0.333 & 0.570 & 0.710 & 1.000 & 0.935 & 0.817 & 0.839 & 0.914 & 0.839 & 0.796 & 0.903 \\
\hline $\begin{array}{l}\text { Park green area per } \\
\text { capita }\end{array}$ & 0.000 & 0.070 & 0.081 & 0.155 & 0.305 & 0.540 & 0.960 & 0.964 & 0.928 & 0.974 & 0.999 & 0.964 & 0.971 & 1.000 \\
\hline $\begin{array}{l}\text { Proportion of } \\
\text { ecological water } \\
\text { consumption in total } \\
\text { water consumption }\end{array}$ & 0.114 & 0.134 & 0.000 & 0.109 & 0.268 & 0.208 & 0.230 & 0.319 & 0.347 & 0.471 & 0.519 & 0.532 & 0.785 & 1.000 \\
\hline Forest coverage & 0.000 & 0.000 & 0.000 & 0.000 & 0.000 & 0.807 & 0.807 & 0.807 & 0.807 & 1.000 & 1.000 & 1.000 & 1.000 & 1.000 \\
\hline
\end{tabular}


Table 6. Status of the regional water circulation health in Hebei Province during 2004-2017

\begin{tabular}{|c|c|c|c|c|c|c|c|c|c|c|c|c|c|c|}
\hline Index & 2004 & 2005 & 2006 & 2007 & 2008 & 2009 & 2010 & 2011 & 2012 & 2013 & 2014 & 2015 & 2016 & 2017 \\
\hline $\begin{array}{l}\text { Water circulation } \\
\text { health index }\end{array}$ & 0.451 & 0.486 & 0.507 & 0.498 & 0.518 & 0.552 & 0.589 & 0.633 & 0.672 & 0.664 & 0.674 & 0.687 & 0.716 & 0.779 \\
\hline $\begin{array}{c}\text { Water circulation } \\
\text { health grade }\end{array}$ & 4 & 4 & 4 & 4 & 4 & 3 & 3 & 3 & 3 & 3 & 3 & 3 & 3 & 2 \\
\hline
\end{tabular}

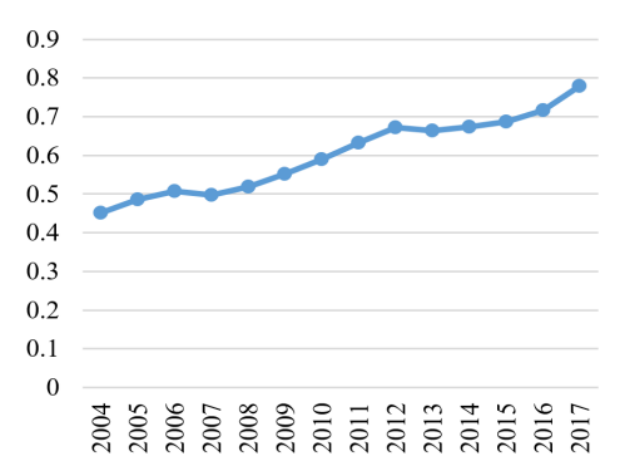

Figure 2. Water circulation health index for Hebei Province

In order to illustrate the status of water circulation health in Hebei Province more visually, a line chart is used, as shown in Figure 2.

According to the evaluation results of the above BP neural network model, in the 14-year evaluation period, the regional water circulation status of Hebei Province during 2004-2008 all fell into Grade 4, which means it was unhealthy, that during 2009-2016 fell into Grade 3, which means it relatively healthy, and that in 2017 fell into Grade 2, which means it was healthy. It can be seen from Figure 2 that the overall water circulation health in Hebei Province from 2004 to 2017 showed a trend of improvement year by year. Specific improvements in water circulation: the daily domestic water consumption per capita was decreasing year by year, indicating that the water conservation department under the government achieved significant results in the management and control of water resources and that people's awareness of water conservation was also enhancing; the proportion of ecological water consumption in total water consumption was constantly increasing, which promoted the healthy circulation of urban water resources; the urban sewage treatment rate increased from $49.17 \%$ in 2004 to $84.50 \%$ in 2017 , indicating that the urban sewage treatment scale and technologies were improving, and that water pollution was being alleviated, and sustainability was already shown from the sewage treatment and water conservation in Hebei Province during the 14 years. However, judging from the results of de-normalization operation, there were also problems in the urban water circulation in Hebei Province: the proportion of investment in wastewater treatment projects in GDP rose from $0.37 \%$ in 2004 to $0.52 \%$ in 2017 , showing an upward trend, but the proportion of investment in wastewater treatment projects is still quite small; the groundwater development and utilization rate was all above $100 \%$ before 2015 , except for $91 \%$ in 2012 , and it was $93.52 \%$ and $99.75 \%$ in 2016 and 2017 , respectively, which means the over-exploitation of groundwater improved, but not to a significant extent.

\section{CONCLUSIONS}

In short, judging from the evaluation results, the status of regional water circulation health in Hebei Province is gradually improving, but as the urbanization rate keeps increasing, the proportion of investment in wastewater treatment projects in GDP is still marginal, and the groundwater development and utilization rate is still high. The negative factors affecting the regional water circulation health in Hebei Province involve all aspects - society, economy, ecological environment, water resources and water management. As indicated by the evaluation results of regional water circulation health and the current severe shortage of water in this province, to solve these problems, in addition to taking some necessary targeted measures, the key is to take the strict control over groundwater resources and surface water resources as a systematic project, and what is more, each city should formulate its own special water conservation plan in line with the local conditions. In this way, the sustainable development and utilization of water resources can be achieved.

Regarding the establishment of the BP neural network model for evaluation of water circulation health, there still remain several issues that are worth discussing. There are various methods to build the water circulation health evaluation system, but an accurate and universally applicable evaluation system has not yet been fully formed. Indices have to be selected according to the characteristics and actual conditions of each urban area, and even different mathematical models are required for calculation. The index system for evaluation of water circulation health in Hebei Province constructed by the BP neural network model is not very accurate for now, and should be improved in the future based on further analysis of the characteristics of water circulation in Hebei Province, so as to continuously reduce the error between the result of the evaluation model and the actual value. In addition, in the proposed BP neural network model for evaluation of water circulation health in Hebei Province, the water circulation health index in some years was hovering around grade boundaries. How to solve this problem will be further studied in the future improvement of the model, so as to achieve more accurate grading of the water circulation health status.

\section{REFERENCES}

[1] Gao, Y., Feng, Z., Li, Y., Li, S. (2014). Freshwater ecosystem service footprint model: A model to evaluate regional freshwater sustainable development-a case study in Beijing-Tianjin-Hebei, China. Ecological Indicators, 39:

1-9. https://doi.org/10.1016/j.ecolind.2013.11.025

[2] Zhang, L., Peng, J., Liu, Y., Wu, J. (2017). Coupling ecosystem services supply and human ecological demand to identify landscape ecological security pattern: A case study in Beijing-Tianjin-Hebei region, China. Urban Ecosystems, 20(3):

701-714. https://doi.org/10.1007/s11252-016-0629-y

[3] Zhang, J., Zhang, C., Shi, W., Fu, Y. (2019). Quantitative evaluation and optimized utilization of water resources- 
water environment carrying capacity based on naturebased solutions. Journal of Hydrology, 568: 96-107. https://doi.org/10.1016/j.jhydrol.2018.10.059

[4] Cao, X., Hu, C., Qi, W., Zheng, H., Shan, B., Zhao, Y., Qu, J. (2019). Strategies for water resources regulation and water environment protection in Beijing-TianjinHebei region. Strategic Study of Chinese Academy of Engineering, 21(5): 130-136. https://doi.org/10.15302/JSSCAE-2019.05.008

[5] Fang, H.Y., Gan, S.W., Xue, C.Y. (2019). Evaluation of regional water resources carrying capacity based on binary index method and reduction index method. Water Science and Engineering, 12(4): 263-273. https://doi.org/10.1016/j.wse.2019.12.008

[6] Liu, D., Qi, X., Li, M., Zhu, W., Zhang, L., Faiz, M.A., Khan, M.I., Li, T.X., Cui, S. (2019). A resilience evaluation method for a combined regional agricultural water and soil resource system based on Weighted Mahalanobis distance and a Gray-TOPSIS model. Journal of Cleaner Production, 229: 667-679. https://doi.org/10.1016/j.jclepro.2019.04.406

[7] Fang, H. (2018). Application of system dynamics and WCCI in water resources evaluation: taking Pakistan as an example. Proceedings of the 2018 International Conference on Mechanical, Electronic, Control and Automation Engineering (MECAE 2018), pp. 896-901. https://doi.org/10.2991/mecae-18.2018.4

[8] Meng, R.F., Yang, H.F., Liu, C.L. (2016). Evaluation of water resources carrying capacity of Gonghe Basin based on fuzzy comprehensive evaluation method. Journal of Groundwater Science and Engineering, 4(3): 213-219.

[9] Zhang, S., Xiang, M., Xu, Z., Wang, L., Zhang, C. (2020). Evaluation of water cycle health status based on a cloud model. Journal of Cleaner Production, 245: 118850. https://doi.org/10.1016/j.jclepro.2019.118850

[10] Li, N., Fan, H.M., Xu, P., Ye, S.F. (2019). Application of BP neural network model in water environmental carrying capacity research of Xiangshan Bay. Journal of Shanghai Ocean University, 28(1): 125-133. https://doi.org/10.12024/jsou.20170802116

[11] Li, Y.W., Cao, K. (2020). Establishment and application of intelligent city building information model based on BP neural network model. Computer Communications, 153: https://doi.org/10.1016/j.comcom.2020.02.013

[12] Shen, Y.H., Kuang, Y.C., Chen, J., Jiang, H. (2017). Ecological water quality assessment system based on BP neural network. Information Technology and Mechatronics Engineering Conference (ITOEC), pp. 6367. https://doi.org/10.1109/ITOEC.2017.8122350

[13] Belousova, A.P. (2000). A concept of forming a structure of ecological indicators and indexes for regions sustainable development. Environmental Geology, 39(11): $1227-1236$ https://doi.org/10.1007/s002549900092
[14] Zhou, Q. (2014). A review of sustainable urban drainage systems considering the climate change and urbanization impacts. Water, 6(4): 976-992. https://doi.org/10.3390/w6040976

[15] Sun, H.P., Xia, X.L., Le, J.J., Huang, H. (2017). Water level prediction based on polyelement correlation analysis and improved bp neural network. 2017 International Conference on Network and Information Systems for Computers, Shanghai, China, pp. 250-253. https://doi.org/10.1109/ICNISC.2017.00061.

[16] Zhou, S., Shen, C. Y., Zhang, L., Liu, N.W., He, T.B., Yu, B. L., Li, J.S. (2019). Dual-optimized adaptive Kalman filtering algorithm based on BP neural network and variance compensation for laser absorption spectroscopy. Optics Express, 27(22): 31874-31888. https://doi.org/10.1364/OE.27.031874

[17] Sun, W., Xu, Y. (2016). Using a back propagation neural network based on improved particle swarm optimization to study the influential factors of carbon dioxide emissions in Hebei Province, China. Journal of Cleaner Production, 112: 1282-1291. https://doi.org/10.1016/j.jclepro.2015.04.097

[18] Li, F., Jia, P., Zhang. Y.X. (2007). Evaluating index system and methods of regional water resources sustainable utilization. Water Conservancy Science and Technology and Economy, 13(11): 826-828. https://doi.org/10.3969/j.issn.1006-7175.2007.11.017

[19] Walmsley, J.J. (2002). Framework for measuring sustainable development in catchment systems. Environmental Management, 29(2): 195-206. https://doi.org/10.1007/s00267-001-0020-4

[20] Nielsen, H., Engelbrecht, J., Brunak, S., Heijne, G.V. (1997). A neural network method for identification of prokaryotic and eukaryotic signal peptides and prediction of their cleavage sites. International Journal of Neural Systems, 8(5-6): 581-599. https://doi.org/10.1142/S0129065797000537

[21] Anderson, J.M. (2006). Integrating recycled water into urban water supply solutions. Desalination, 187(1-3): 19. https://doi.org/10.1016/j.desal.2005.04.062

[22] Zhang, J., Zhang, Y., Wang, Z., Duan, J., Huang, X. (2019). An efficient optimization algorithm for extreme value of nonlinear function based on the SAGA and BP algorithm. IEEE Access, 7: 133058-133068. https://doi.org/10.1109/ACCESS.2019.2922451

[23] Acheampong, A.O., Boateng, E.B. (2019). Modelling carbon emission intensity: application of artificial neural network. Journal of Cleaner Production, 225: 833-856. https://doi.org/10.1016/j.jclepro.2019.03.352

[24] Chen, Y., Shen, L., Li, R., Xu, X., Hong, H., Lin, H., Chen, J. (2020). Quantification of interfacial energies associated with membrane fouling in a membrane bioreactor by using BP and GRNN artificial neural networks. Journal of Colloid and Interface Science, 565: 1-10. https://doi.org/10.1016/j.jcis.2020.01.003 